\title{
The effect of the global warming and environmental temperature on the animal's molecular response and enzymatic activity
}

\begin{abstract}
The impact of climate change has been significant to threaten human health via different parameters. Temperature is a dangerous abiotic factor which affects organisms on its ecological level through infiltrating its molecular and cellular levels. Temperature is a measure of the kinetic energy of the molecules in a system. Environmental temperature has direct effect on molecular response and enzymatic activity of animals. This article is a short communication of the effect of the global warming and environmental temperature on the animal's molecular response and enzymatic activity.
\end{abstract}

Keywords: environmental temperature, climate change, molecular response, enzymatic activity
Volume 9 Issue 2 - 2020

\author{
Tahereh Alinejad,' Subha Bhassu, ${ }^{1,2}$ Rofina \\ Yasmin Othman, ${ }^{2}$ Firuza Begham Binti \\ Mustafa $^{3}$ \\ ${ }^{1,3}$ Department of Genetics and Molecular Biology, Institute of \\ Biological Sciences, University of Malaya, Malaysia \\ ${ }^{2}$ Centre for Research in Biotechnology for Agriculture(CEBAR), \\ University of Malaya, Malaysia \\ ${ }^{3}$ Department of Geography, Faculty of arts and social sciences, \\ University of Malaya, Malaysia
}

\begin{abstract}
Correspondence: Subha Bhassu Tahereh Alinejad, Department of Genetics and Molecular Biology, Institute of Biological Sciences, University of Malaya, Malaysia, Tel 0060182322036 , 0060196760550

Emailsubhabhass@um.edu.my,Talineja698@gmail.com
\end{abstract}

Received: February 24, 2020 | Published: March 12, 2020

\section{Introduction}

The intergovernmental panel on climate change officially released an important report that addressed the global warming impact on living phenomena on the earth. ${ }^{1}$ The environmental temperature might have many fluctuations for many creatures throughout their lives. This effect may occur yearly, seasonally, or daily and usually does not remain constant. There is a question to ponder on, and that is that how an organism struggles with long-term or severe temperature changes. ${ }^{2}$ Initial heat shock research investigates the mechanisms behind the response to critical heat stress by observing the heat shock in Drosophila. In this study, puffs characteristics had been studied in the salivary gland chromosomes of Drosophila. ${ }^{3}$ Later, it was understood that these studied chromosomal puffs were associated with RNA synthesis and heat shock protein expression. Since 1974 up till now, it is well known that heat shock protein family including (e.g, Hsp100, Hsp90, Hsp70, Hsp60, Hsp40 and small heat shock protein families) are regulated under "heat shock response" mechanisms in almost all organisms. ${ }^{4}$ The heat shock proteins are grouped by size or categorized by function. They are also famed as molecular chaperones because they are involved in protein folding. It has also been reported that they are preventing the formation of protein accumulation inside the cell. ${ }^{5}$ Additionally, it has been reported that they have functions in ATP-independent ' (small heat shock proteins) ATP-dependent (Hsp60, Hsp70) mechanisms. ${ }^{6}$ Initial studies revealed that the binding of the heat shock factor (HSF) to cis-regulatory heat shock element (HSE) regions induced heat shock regulatory networks. Furthermore, interaction between Hsp70 with HSF and can cause heat shock auto regulation or block it. ${ }^{7}$
Researchers have approved that the heat stress response is a complicated mechanism. Research has also confirmed that the heat shock response has a variation in the initiation or termination timing or in the stress intensity. It furthermore depends on different types of Hsps in different organisms. It also may comprise from the induction of many other non Hsps genes. ${ }^{4,8-11}$

The comparison between Drosophila and mussel Mytilus trossulus showed that in the Drosophila heat shock protein is synthesized during heat stress, but it will only be expressed after stress in mussel Mytilus trossulus. A range of HSPs proteins involved in response to heat were detected by faint SDS-PAGE bands in marine snails, yeast, and mussels. Hsps protein also maintains a fundamental influence for thermos-tolerance in yeast. ${ }^{12}$

Moreover, recent work on Drosophila and yeast has exposed no limitation in the binding target of the HSF to heat shock proteins. This confirmed that almost $3 \%$ of genomic loci are available as binding target. ${ }^{13}$ The recent interest in gene and mechanisms characterizations has risen by the development of genomic tools. The accessibility to the heat shock response studies by gene expression monitoring on a wide-ranging scale by high throughput technology and quantitative PCR has increased. ${ }^{14}$ Post research has shown that the level of change in gene and protein expression are not essentially correlated. Recent researches have confirmed that by some protein regulations. For instance (e.g., elongation factors) showed that these proteins are expressed at the translational level, but not in protein level or vice versa. This means that an increased in this gene expression generally does correlate with an increase in their protein expression. ${ }^{15}$ Moreover, 
additional research on Drosophila confirmed a parallel linkage between genomic and metabolomic profiles resulting in heat stress.

Previously, most studies had focused on simple modeled organisms such as prokaryotes, Drosophila, and yeast. Recent studies; however, focused on the heat shock response in higher organisms. ${ }^{12}$ Heat stress can cause many types of changes, fluctuations or variations in higher organisms or animals? Higher organisms including animals are living in different habitat and are widely exposed to a range of biophysical challenges. They are widely exposed to temperature fluctuations. These creatures may counteract these challenges by increasing or decreasing their body temperatures through adaptation process. ${ }^{16}$

A noteworthy example is the T. funerals an aquatic animal which was monitored in a study for 26 days from March-April. Nearly after half of the 26 days, the water temperature was midday low, but the body temperature was $27^{\circ} \mathrm{C}$, its body temperature was high enough to induce Hsp70 and Hsp90 gene expressions. ${ }^{17}$

Fascinatingly, in the similar heat stress condition, before midday (2.5h at $\left.30^{\circ} \mathrm{F}\right), \mathrm{Hsp} 70, \mathrm{Hsp} 38$, Hsp90, and Hsp77 expression was increased and after $6 \mathrm{~h}, 30 \mathrm{~min} ., 6 \mathrm{~h}$, and $14 \mathrm{~h}$ it dropped to normal levels, this showed that $T$. funebrails can tolerate the stress response during the two low-temperature waves. ${ }^{17}$ In addition, the up-regulated HSPs levels that contribute to survival with reversible protein denaturation also exist following heat stress in the studied area. Reversible protein denaturation is the mechanism that can handle the reversible denaturation through protein degradation. ${ }^{16}$

There are some studies on the recovery from temperature fluctuation of intertidal specious such as mussel M. trossulus and crab, Petrolisthes cinctipes. Studies on the heat shock response in these species have confirmed the immersion of Hsp70 and Hsp90 in reversible protein denaturation. ${ }^{18}$ In this stage, a question arises that, what other mechanisms might be affected in response to the thermal stress? And a serious question will rise, which does of the temperature have effect on the enzymatic Activity?

All enzymes have a range of temperatures for their activity. In eukaryotes the enzymes have an optimum temperature that is the best reaction for their optimum enzymatic activity which in human is around $37^{\circ}, 98.6^{\circ} \mathrm{F}$, the normal body temperature. Enzymes activity has interdependent interaction with temperature. ${ }^{19}$ All the animals have the adaptation capacity to the limited range of the environmental temperature. Animals from hot climates such as desert and tropical climates adopt their enzymatic activity to the highest optimum range while animals from cold climate adapt their enzymatic activity to the lowest optimum range. ${ }^{20}$ Even though that the animals have this adaptation capacity to the temperature limits, still there is a limited tolerance range for their enzymatic activity and survival. ${ }^{21}$ This limited ranges are the two ends of an enzyme activity in which the enzyme activations start up to the protein break down. Enzymes are proteins and they will break down at temperatures above 40 degrees Celsius or $104^{\circ} \mathrm{F}^{22}$

Enzymes are protein molecules that would be activated in their tertiary structure. An enzyme may become inactive by an inhibitor or under advert thermal circumstances. The enzyme activity would reach to its highest range in the optimum thermal condition and will decrease in high temperature due to denaturation. Most of the animal enzyme will lose their activity above $40^{\circ} \mathrm{C}$. In high temperature the active site of the enzyme will be denatured and loose its 3D structure. So, temperature has a strong effect on enzyme activity. ${ }^{23}$ And the deficiency in enzymatic activity will subsequently case an cause respiratory diseases due to the Cardiovascular disease, mental health, ${ }^{24-27}$ and different types of the cancer. ${ }^{28}$

\section{Conclusion}

Even though the IPCC reports which addressed the global warming impact on earth had been officially released in 2014, the effect of temperature on animal health had been neglected. It's clear that the environmental temperature has a direct effect on body temperature and subsequently on the enzymatic activity as an environmental stressor. All animals are threatened by the fluctuations in environmental temperature, caused by global warming. It has become critical to determine the scope of molecular research on climate change and the associated animals and human health impact. So, to the authors point of view, such studies that report gene-environment interaction under different circumstance, contribute to make more insights into the role of the genes, proteins and cell structures in living organisms' adaption to the advert climate circumstances.

\section{Acknowledgments}

None.

\section{Conflicts of interest}

The author declares that there are no conflicts of interest.

\section{Funding}

None.

\section{References}

1. Pachauri RK, Allen MR, Barros VR, et al. Climate change 2014: synthesis report. Contribution of Working Groups I, II and III to the fifth assessment report of the Intergovernmental Panel on Climate Change(IPCC). 2014

2. Hochachka P, Somero G. Biochemical adaptation: mechanism and process in physiological evolution: Oxford University Press. 2002;30(3):480.

3. Ritossa F. A new puffing pattern induced by temperature shock and DNP in Drosophila. Experientia. 1962;18(12):571-573.

4. Lindquist S. The heat-shock response. Annual review of biochemistry. 1986;55(1):1151-1191.

5. Parsell D, Lindquist S. The function of heat-shock proteins in stress tolerance: degradation and reactivation of damaged proteins. Annual review of genetics. 1993;27(1):437-496.

6. Fink AL. Chaperone-mediated protein folding. Physiological reviews. 1999;79(2):425-449.

7. Morimoto RI, Santoro MG. Stress-inducible responses and heat shock proteins: new pharmacologic targets for cytoprotection. Nature biotechnology. 1998;16(9):833.

8. Brokordt K, Pérez H, Herrera C, et al. Reproduction reduces HSP70 expression capacity in Argopecten purpuratus scallops subject to hypoxia and heat stress. Aquatic Biology. 2015;23(3):265-274.

9. Junprung W, Supungul P, Tassanakajon A. HSP70 and HSP90 are involved in shrimp Penaeus vannamei tolerance to AHPND-causing strain of Vibrio parahaemolyticus after non-lethal heat shock. Fish \& shellfish immunology. 2017;60:237-246.

10. Madeira D, Luís Narciso, Henrique N Cabral, et al. Role of thermal niche in the cellular response to thermal stress: Lipid peroxidation and HSP70 expression in coastal crabs. Ecological indicators. 2014;36:601-606. 
11. Ravaux J, Léger N, Rabet N, et al. Plasticity and acquisition of the thermal tolerance (upper thermal limit and heat shock response) in the intertidal species Palaemon elegans. Journal of Experimental Marine Biology and Ecology. 2016;484:39-45.

12. Hoffmann JA. The immune response of Drosophila. Nature. $2003 ; 426(6962): 33-38$

13. Hahn JS, Hu Z, Thiele DJ, et al. Genome-wide analysis of the biology of stress responses through heat shock transcription factor. Molecular and cellular biology. 2004;24(12):5249-5256.

14. Birch-Machin I, Gao S, Huen D, et al. Genomic analysis of heat-shock factor targets in Drosophila. Genome biology. 2005;6(7):R63.

15. Suzuki K, Suzuki I, Leodolter A, et al. Global DNA demethylation in gastrointestinal cancer is age dependent and precedes genomic damage. Cancer cell. 2006;9(3):199-207.

16. Hofmann GE, Lund SG, Place SP, et al. Some like it hot, some like it cold: the heat shock response is found in New Zealand but not Antarctic notothenioid fishes. Journal of Experimental Marine Biology and Ecology. 2005;316(1):79-89.

17. Tomanek L, Somero GN. Evolutionary and acclimation-induced variation in the heat-shock responses of congeneric marine snails (genus Tegula) from different thermal habitats: implications for limits of thermotolerance and biogeography. Journal of Experimental Biology. 1999;202(21):2925-2936

18. Stillman JH. Acclimation capacity underlies susceptibility to climate change. Science. 2003;301(5629):65-65.

19. Rodrigues RC, Ortiz C, Berenguer-Murcia Á, et al. Modifying enzyme activity and selectivity by immobilization. Chem Soc Rev. 2013;42(15):6290-6307.
20. Bilal M, Iqbal HM. Naturally-derived biopolymers: Potential platforms for enzyme immobilization. Int J Biol Macromol. 2019;130:462-482.

21. Jiang W, Li J, Gao Y, et al. Effects of temperature change on physiological and biochemical responses of Yesso scallop, Patinopecten yessoensis. Aquaculture. 2016;451:463-472.

22. Sinsabaugh RL, Lauber CL, Weintraub MN, et al. Stoichiometry of soil enzyme activity at global scale. 2008;11(11):1252-1264.

23. Wei Y, Wu D, Wei D, et al. Improved lignocellulose-degrading performance during straw composting from diverse sources with actinomycetes inoculation by regulating the key enzyme activities. Bioresour Technol. 2019;271:66-74.

24. Ito K, De Leon SF, Lippmann MJE. Associations between ozone and daily mortality: analysis and meta-analysis. Epidemiology. 2005;16(4):446-457.

25. Zanobetti A, Schwartz J. Air pollution and emergency admissions in Boston, MA. J Epidemiol Community Health. 2006;60(10):890-895.

26. Fritze JG, Blashki GA, Burke S, et al. Hope, despair and transformation: climate change and the promotion of mental health and wellbeing. Int $J$ Ment Health Syst. 2008;2(1):13.

27. Page LA, Howard LM. The impact of climate change on mental health (but will mental health be discussed at Copenhagen?). Cambridge university press. 2010;40(2):177-180.

28. Seyfried TN. Cancer as a mitochondrial metabolic disease. Front Cell Dev Biol. 2015;3:43. 